\title{
Asymmetric septal hypertrophy and hypertrophic cardiomyopathy
}

\author{
RICHARD EMANUEL, JIANIS MARCOMICHELAKIS, RONALD WITHERS, KAY O'BRIEN
}

From the National Heart Hospital and Cardiothoracic Institute, London, Department of Cardiology, The Middlesex Hospital, and Department of Biology as applied to Medicine, The Middlesex Hospital, Medical School, London

SUMMARY Nineteen families were selected for study in which hypertrophic cardiomyopathy and/or isolated asymmetric septal hypertrophy occurred in successive generations. All 19 propositi had hypertrophic cardiomyopathy proven by cardiac catheterisation and angiocardiography (eight), operation (four), or necropsy (seven). These 19 families consisted of the 19 propositi and their 39 siblings, 38 parents, and 23 children. Of these 119, 114 were examined or, if dead before the study, there was sufficient evidence from necropsy or operation reports to establish the diagnosis. In five (four parents and one sibling) who had died before the study there was insufficient evidence to establish the presence or absence of heart disease. These 19 families were selected from over one hundred cases of familial cardiomyopathy with a minimum follow up of five years. The main points leading to selection were the presence of the disease in two successive generations and the availability of the first degree relatives for examination.

The families were divided into two subsets. One consisted of 12 families where not only the propositus had all the clinical manifestations of hypertrophic cardiomyopathy but so did one of the parents. In the second subset of seven families, the propositus had proven hypertrophic cardiomyopathy, but one of the parents had isolated asymmetric septal hypertrophy, with no other manifestation of cardiovascular disease. For the purpose of this study differentiation was made between relatives with clinical, radiological, electrocardiographic, and echocardiographic signs of hypertrophic cardiomyopathy, and those in whom the only abnormality was in the interventricular septum and detected solely by echocardiography. The term isolated asymmetric septal hypertrophy was applied to the latter if the interventricular septal:posterior left ventricular wall (IVS/PLVW) ratio was 1.3 or more, when allowance had been made for the thickening of the interventricular septum which occurs with age.

In the 12 families (subset I) where both the propositi and one parent had hypertrophic cardiomyopathy, there were the 12 propositi with 22 siblings. Nineteen of these 34 were found to have hypertrophic cardiomyopathy and one had isolated asymmetric septal hypertrophy; thus there were 20 affected. In the seven families (subset II) in which the propositi had proven hypertrophic cardiomyopathy and one of the parents had isolated asymmetric septal hypertrophy, there were the seven propositi with 17 siblings. Eleven of these 24 had hypertrophic cardiomyopathy and one had isolated asymmetric septal hypertrophy; thus 12 were affected. Applying Smith's method of analysis, the expected number affected if the condition was inherited as a dominant characteristic was 20.1 in subset I and 13.4 in subset II. These figures did not differ significantly from those actually found, that is 24 and 12 , respectively.

The conclusions are that in familial hypertrophic cardiomyopathy isolated asymmetric septal hypertrophy is part of the clinical spectrum and has the same genetic implications as hypertrophic cardiomyopathy. Thus parents with clinical hypertrophic cardiomyopathy can produce offspring with either isolated asymmetric septal hypertrophy or clinical hypertrophic cardiomyopathy. Con- 
versely, parents with isolated asymmetric septal hypertrophy can produce children with either $\stackrel{\varrho}{7}$

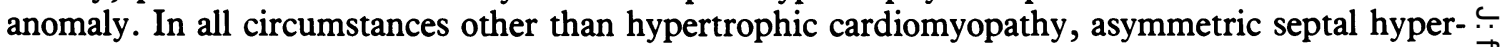
trophy does not appear to be an inherited characteristic.

Asymmetric septal hypertrophy can no longer be considered the "unifying link" in hypertrophic cardiomyopathy. ${ }^{1}$ It occurs in a small percentage of normal adults, is common in infants, ${ }^{23}$ may be present in athletes, ${ }^{4}$ and it is also seen in cases of congenital heart disease, particularly where the right ventricle is involved. ${ }^{5-9}$ It is not uncommon in fixed aortic valve stenosis ${ }^{70}$ and it also occurs in hypertension ${ }^{11}$ and coronary artery disease, especially with inferior infarction. ${ }^{12}{ }^{13}$ Conversely, it is occasionally absent in cases of hypertrophic cardiomyopathy where the disarrayed muscle involves the free wall of the left ventricle as extensively as the interventricular septum. ${ }^{14-16}$

Confusion will arise if the term asymmetric septal hypertrophy is used synonymously with hypertrophic cardiomyopathy. It is suggested that the latter should be used to describe cases with clinical, radiological, electrocardiographic, and echocardiographic evidence of the disease, which will include asymmetric hypertrophy of the interventricular septum. The term asymmetric septal hypertrophy, qualified by the word isolated, should be confined to those cases where the sole abnormality is in the interventricular septum, detected only by echocardiography, and where there is no clinical, radiological, or electrocardiographic evidence of cardiovascular disease.

The problem is exemplified by Clark et al. ${ }^{17}$ who referred to 44 first degree relatives with asymmetric septal hypertrophy. In $77 \%$ there were abnormalities in the history, physical examination, or electrocardiogram, but in the remaining $23 \%$ the abnormalities were confined to the interventricular septum. Similarly, in 27 first degree relatives reported by Van Dorp et al. ${ }^{18}$ and referred to as having asymmetric septal hypertrophy, $83 \%$ were clinically affected, but in $17 \%$ the abnormality was confined to the interventricular septum. The same was the case with the first degree relatives reported by Ten Cate et al. ${ }^{19}$ where only the minority had abnormalities confined to the interventricular septum.

In this study a differentiation has been made between relatives with clinical, radiological, electrocardiographic, and echocardiographic evidence of hypertrophic cardiomyopathy and those in whom the only abnormality was in the interventricular septum, detected solely by echocardiography. The term isolated asymmetric septal hypertrophy has been confined to the latter. An interventricular septum to posterior left ventricular wall (IVS/PLVW) ratio of 1.3 or more was considered abnormal when allowance

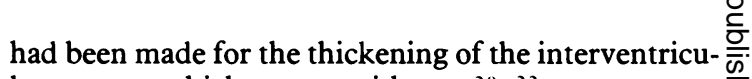
lar septum which occurs with age. $20^{-22}$

The purpose of this study was to examine the $\stackrel{\varnothing}{\varrho}$ association of isolated asymmetric septal hypertrophy o and its relation to hypertrophic cardiomyopathy in $\overrightarrow{0}$ selected families.

\section{Subjects and methods}

Nineteen families were selected for study in which the propositus had hypertrophic cardiomyopathy proven ${ }^{\circ}$ by cardiac catheterisation and angiocardiography (eight), operation (four), or necropsy (seven). These $\triangle$ were divided into two subsets. In the first there were $\vec{\square}$ 12 families where not only the propositus but also one of the parents had all the clinical, radiological, electrocardiographic, and echocardiographic manifesta- $\vec{\oplus}$ tions of hypertrophic cardiomyopathy. In the second group of seven families the propositus had proven hypertrophic cardiomyopathy but one parent had iso-lated asymmetric septal hypertrophy without any other manifestation of cardiovascular disease. These 19 families consisted of the 19 propositi and their 39ळ siblings, 38 parents, and 23 children. Of these $119 \stackrel{2}{\rightrightarrows}$ first degree relatives, 114 were examined or, if dead before the study, there was sufficient evidence avail- $\frac{}{T}$ able from previous medical examinations or from necropsy or operation reports to establish the presence or absence of heart disease. There were five exceptions, $\mathbb{\Phi}$ four parents (54.I.1, 72.I.1, 73.I.1, and 93.I.1) and? one sibling (72.II.4) who died before study and with-o out adequate information available for a diagnosis to be made.

As in previous studies, ${ }^{23-27}$ arrangements were made to interview the propositus or a close relative at? home and a family pedigree was drawn up which $>$ included all first, second, and third degree relatives. Because of the problem of availability the analysis was confined to first degree relatives as by so doing it was possible to examine or obtain reliable information on $N$ $\mathbf{9 5 . 8 \%}$ of the sample. During the interview, specifice questions were asked to ascertain whether any relative was known to have a cardiac abnormality. Parentsso siblings, and children of the propositi who were wil-क ling to co-operate were examined at the National ${ }^{\text {? }}$ Heart Hospital, The Middlesex Hospital, or a conve- 0 nient regional hospital. Examination involved physi-웅 cal examination, chest radiography, electrocardiogra $-\Omega$ phy, and echocardiography. If the examination wasi done at a regional hospital, all the chest radiographso 
Table 1 Analysis of propositi and siblings from 19 families

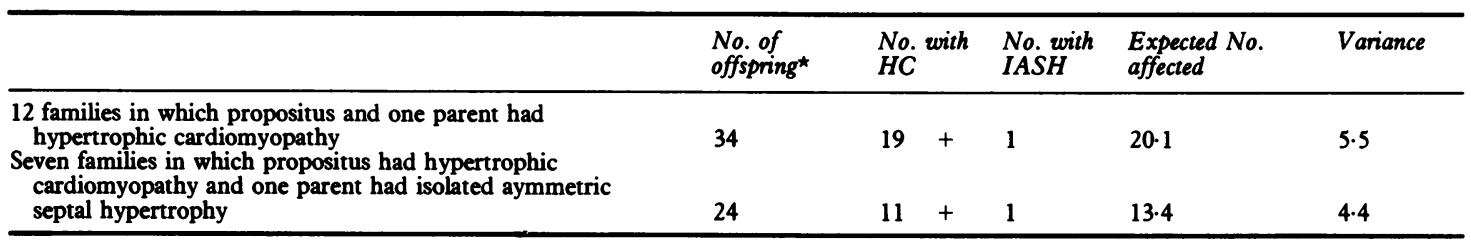

In 12 of the families both propositus and one parent had hypertrophic cardiomyopathy; in the remaining seven the propositus had hypertrophic cardiomyopathy and one parent isolated asymmetric septal hypertrophy. Figures for the expected number affected, assuming a dominant inheritance $\left(\mathrm{Smith}^{28}\right)$, are also shown. ${ }^{\star}$ Offspring=propositi and their siblings.

and electrocardiograms were sent to one of us (RE). All echocardiograms were done by JM at The Middlesex Hospital using a Smith Kline Ekoline 20A and a $2.25 \mathrm{MHz}$ Transducer focused at $7.5 \mathrm{~cm}$ coupled to a Cambridge six channel fibreoptic recorder. Recordings were made with the subject lying on the left side. The mitral valve echocardiogram was recorded from a transducer in the third, fourth, or fifth intercostal space, perpendicular to the chest wall. Aortic valve echoes were identified by tilting the transducer medially and superiorly from the mitral valve position. The interventricular septal and free posterior left ventricular wall echoes were recorded at both mitral and submitral levels, measurements being made at the $Q$ wave inscription of the electrocardiogram.

\section{Results}

The 19 families were divided into two groups. In the 12 families where both the propositus and one parent had hypertrophic cardiomyopathy there were 12 propositi with their 22 siblings. Nineteen of these 34 (one of the siblings (72.II.4) was not examined) were found to have hypertrophic cardiomyopathy and one
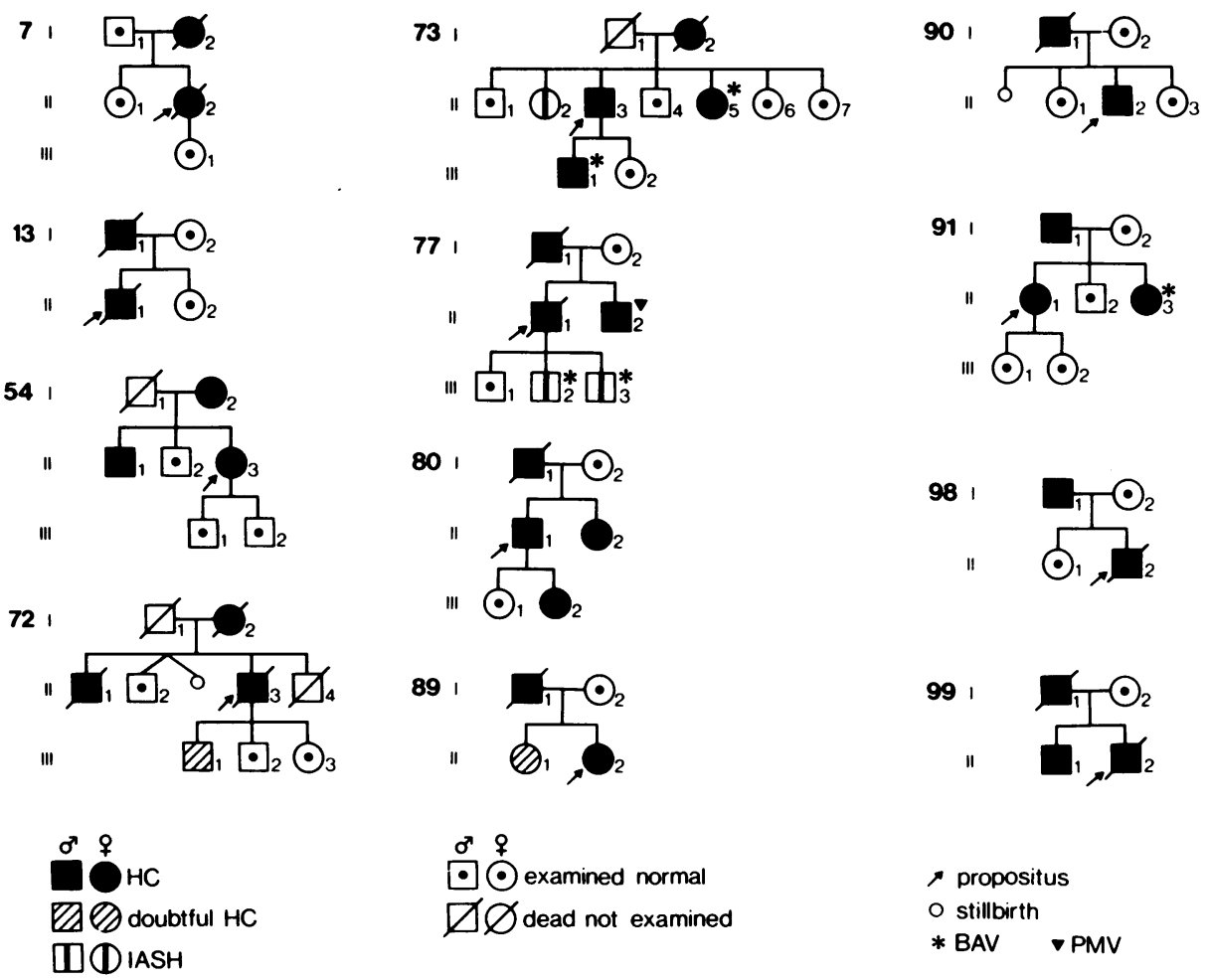

Fig. 1 Pedigrees of 12 families in which the propositus and one parent had hypertrophic cardiomyopathy. The doubtful cases (72.III.1 and 89.II.1) have been considered normal for the purposes of the statistical analysis. In the three relatives who may have additional congenitally bicuspid aortic valve $(B A V)$ diagnostic details are given in Table 2. HC, hypertrophic cardiomyopathy. IASH, isolated asymmetric septal hypertrophy. PMV, prolapsed mitral valve. 
had isolated asymmetric septal hypertrophy; thus there were 20 affected. Analysing these figures according to Smith, ${ }^{28}$ who allowed for the inevitable truncate selection of this type of material, if the condition was inherited as a dominant characteristic the predicted number affected would be 20.1 which was not significantly different from our findings of 19 or 20 if the one sibling with isolated asymmetric septal hypertrophy was included. Considering the seven families in which the propositus had proven hypertrophic cardiomyopathy and one of the parents isolated asymmetric septal hypertrophy, there were the seven propositi and their 17 siblings. Examination showed 11 of these 24 had hypertrophic cardiomyopathy and one had isolated asymmetric septal hypertrophy; thus 12 were affected. Again applying Smith's ${ }^{28}$ analysis, if the inheritance was dominant the expected number of affected would be 13.4 which again did not differ significantly from our findings of 11 or 12 if the sibling with isolated asymmetric septal hypertrophy was included; thus in neither subgroup was there a significant difference between our results and those expected for a dominant mode of inheritance (Table 1). Pedigrees of the 19 families are given in Fig. 1 and 2. In three siblings (32.II.3, 89.II.1, and 93.II.I) the diagnosis was uncertain. In the pedigrees they have been shown as "doubtful hypertrophic car- $\stackrel{\varrho}{7}$

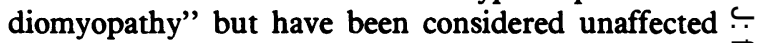
for the purpose of the above analysis. The clinical $\underset{\vec{O}}{\vec{\rho}}$ details of the 12 parents, 11 siblings (seven in subset I; four in subset II), and three children with hypertrophic cardiomyopathy are given in Table 2.

The echocardiographic data leading to the diagnosis of isolated asymmetric septal hypertrophy in the two siblings and seven parents are given in Table 3 . Henry is et al. ${ }^{29}$ have examined 92 normal persons using $\vec{\circ}$ M-mode echocardiography and have produced regression equations with limits for septal thickness and $\vec{\omega}$ posterior ventricular wall thickness. Using these equations for the two siblings and seven parents we find that the interventricular septal measurements fall out- $\vec{c}$ side the $95 \%$ prediction interval for normal subjects, whereas the posterior left ventricular wall thicknesses 0 are well within normal limits, thus confirming the diagnosis of isolated asymmetric septal hypertrophy (Table 3). It should be noted that Marcomichelakis $\vec{\square}$ et al. ${ }^{22}$ in their analysis of 100 normal male subjects, 음. found that there was not only an increase in the IVS/ PLVW ratio with age, but also an increase in the $\varnothing$ scatter of the ratios after the age of 40 years. Assuming the same is true for female subjects, the two siblings and seven parents had an IVS/PLVW ratio at or

Table 2 Clinical findings in 12 parents, 11 siblings, and three children with hypertrophic cardiomyopathy

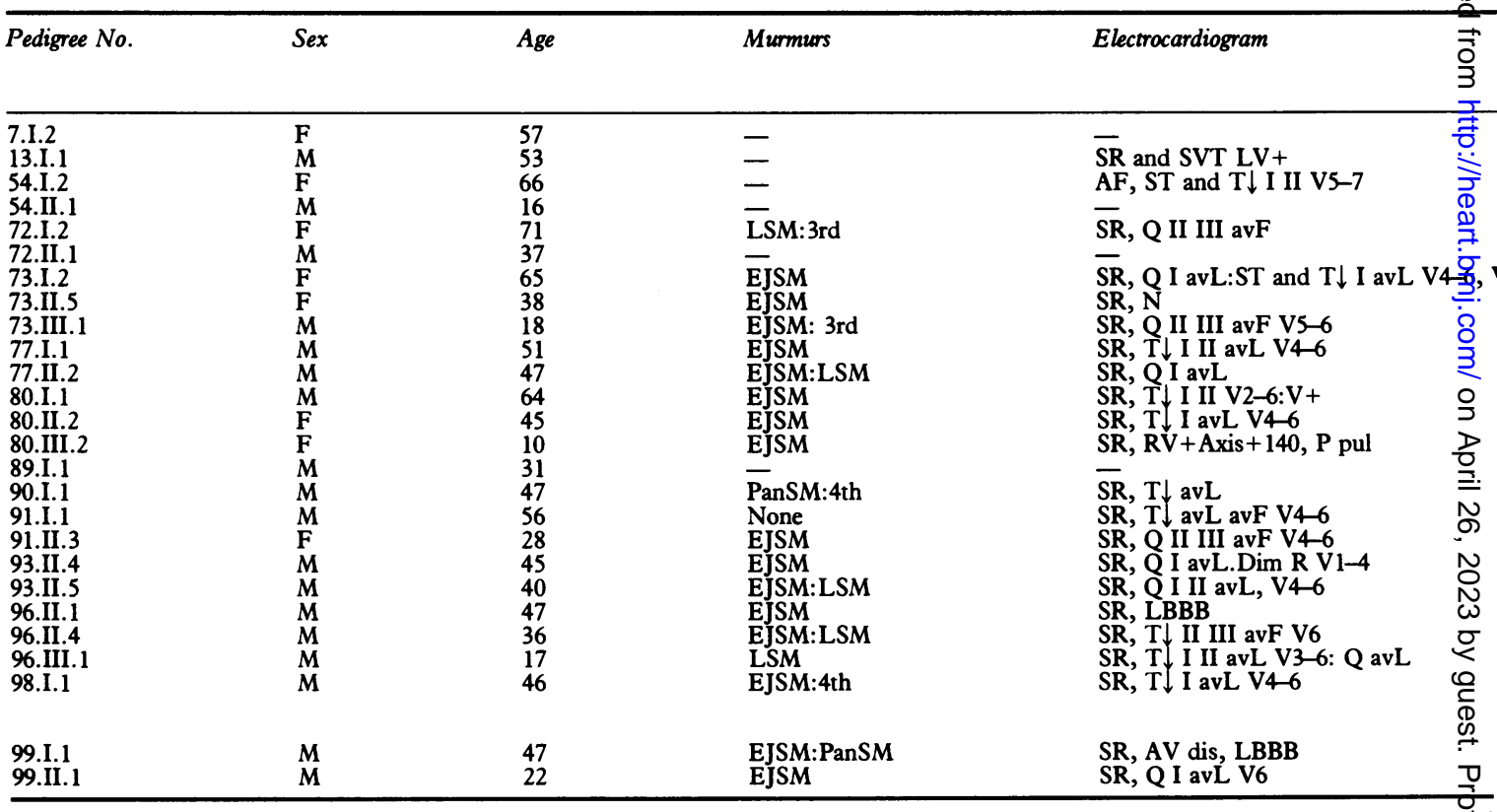

Note: The 19 propositi have been omitted. Doubtful cases (32.II.3, 33.III.4, 72.III.1, 89.II.1, and 93.II.1, see Fig. 2) have also been Abbreviations used are as follows: 3rd, third heart sound; 4 th, fourth (atrial) heart sound; EJSM, ejection systolic murmur; LSM, late systolic Gu PanSM, pansystolic murmur; SR, sinus rhythm; SVT, supraventricular tachycardia; AF, atrial fibrillation; AV dis, atrioventricular dissociation increased voltage (S V2 or V3+R V5 or V6 $>35 \mathrm{~mm}$ ); P pul, P pulmonale; Dim R V1-4, diminishing R wave V1-4; LBBB, left bundle-branen $x$-ray+, enlarged heart; Im IVS, impaired movement of interventricular septum; EC AV CL, eccentric aortic valve closure; SAM, systoliçin 

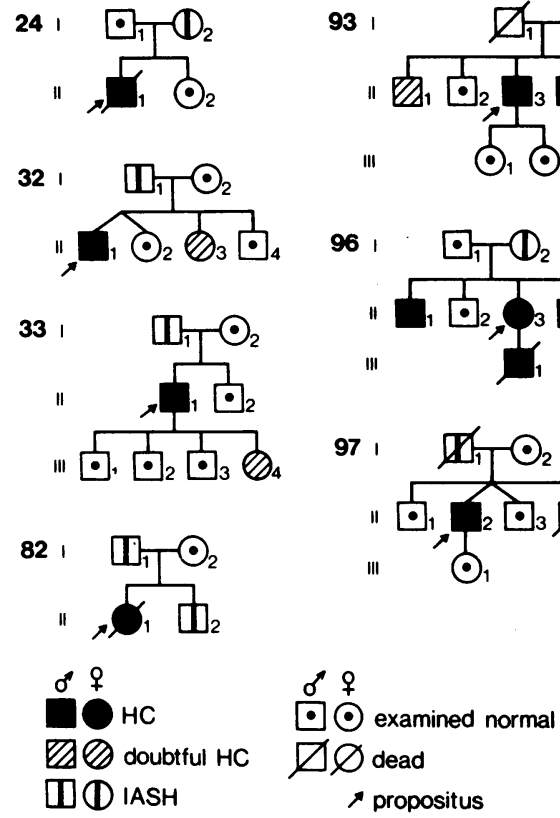

Fig. 2 Pedigrees of seven families in which the propositus had hypertrophic cardiomyopathy and one of the parents isolated asymmetric septal hypertrophy. The doubtful cases (32.II.3, 33.III.4 and 93.II.1) have been considered normal for the purposes of the statistical analysis. exceeding the upper 95 centile for their age. ${ }^{22}$

By definition in all cases of isolated asymmetric septal hypertrophy the sole abnormality was in the interventricular septum. All nine cases in Table 3 were considered normal after clinical examination which included an electrocardiogram and chest radiograph, but after the echocardiogram had been found abnormal these data were reviewed. In two relatives there were minor abnormalities which had previously been accepted as normal, mainly on account of the patients' ages, but in retrospect these findings were probably related to the abnormal interventricular septum. In one man aged 67 (33.I.2), there was a soft (grade 1/6) apical late systolic murmur, and in one woman, aged 65 (96.I.2), the electrocardiogram showed a partial right bundle-branch block.

\section{Discussion}

When considering the thickness of the interventricular septum as a specific measurement or comparing it with the thickness of the posterior left ventricular wall as a ratio, it is important to appreciate that both bf - me thicker with age, particularly the interventricúlar septum. More relevant, perhaps, is the scatter in the IVS/PLVW ratios, which occurs above the age of 40 years, and great caution must be exercised

\begin{tabular}{|c|c|c|c|c|c|}
\hline \multirow[t]{2}{*}{ est $x$-ray } & \multicolumn{2}{|c|}{ Echocardiogram } & \multirow[t]{2}{*}{ Catheter } & \multirow[t]{2}{*}{ Dead/Alive } & \multirow[t]{2}{*}{ Other information } \\
\hline & IVS/PLVW & Other observations & & & \\
\hline \multirow{22}{*}{1} & $\overline{-}$ & - & $\overline{-}$ & $\begin{array}{l}+57 \\
+53\end{array}$ & Sudden + PM \\
\hline & $\overline{\mathbf{R}}$ & $\overline{\mathbf{R}}$ & $\overline{\mathbf{L V}}++$ No Grad & A & Sudden $+\mathbf{P M}$ \\
\hline & - & - & & +16 & Sudden + PM Ht wt $340 \mathrm{~g}$ \\
\hline & - & - & - & +73 & Sudden + PM \\
\hline & $\overline{20}$ & - & - & +37 & Sudden+PM Ht wt $410 \mathrm{~g}$ \\
\hline & $\begin{array}{l}2.0 \\
1.6\end{array}$ & $\overline{\mathrm{EC}} \mathrm{AV} \mathrm{CL}$ & E & +69 & $\begin{array}{l}\text { Sudden }+ \\
\text { BAV }\end{array}$ \\
\hline & 1.5 & Im IVS & - & A & ? BAV \\
\hline & - & & - & +59 & PM \\
\hline & 1.7 & Im IVS:PMV & - & A & - \\
\hline & $\overline{1.5}$ & & $\overline{-}$ & +64 & - \\
\hline & 1.5 & SAM & 二 & $\begin{array}{l}\mathbf{A} \\
\mathbf{A}\end{array}$ & 二 \\
\hline & - & - & $\mathrm{LV}++$ Grad $50 \mathrm{~mm}$ & +31 & Sudden + PM \\
\hline & - & - & & +53 & Sudden+PM Ht wt $510 \mathrm{~g}$ \\
\hline & 1.7 & Im IVS & - & A & - \\
\hline & 1.5 & EC AV CL & - & $\mathbf{A}$ & ? BAV \\
\hline & 1.7 & Im IVS & - & A & - \\
\hline & 1.6 & Im IVS & - & A & - \\
\hline & 1.4 & - & - & $\ddot{A}$ & - \\
\hline & 1.5 & SAM & $\overline{-}$ & $\stackrel{\mathbf{A}}{+21}$ & $\bar{s}$ \\
\hline & 1.5 & $\begin{array}{l}\text { Im IVS } \\
\text { SAM: } \\
\text { EC AV CL }\end{array}$ & $\overline{\mathrm{LV}}++\mathrm{Grad} 60 \mathrm{~mm}$ & $\mathbf{A}$ & $\begin{array}{l}\text { Confirmed at surgery } \\
\text { AV normal }\end{array}$ \\
\hline & - & ${ }_{-}^{\text {Mid Sys CL }}$ & $\mathrm{LV}++\mathrm{Grad} 10 \mathrm{~mm}$ & +53 & \\
\hline & $\overline{1 \cdot 2}$ & - & $\underline{L}++$ Grad $10 \mathrm{~mm}$ & +3 & (see text) \\
\hline
\end{tabular}

wement of mitral valve; PMV, prolapsed mitral valve; Mid Sys CL, mid systolic closure of aortic valve; $R$, echo refused; Grad, gradient; LV, left ntricle; PM, post mortem examination; BAV, congenitally bicuspid aortic valve. In the three with "? BAV" the diagnosis was only suspected because of : AV CL and an EJSM; the latter may well be irrelevant having arisen from elsewhere in the left ventricular outflow tract. Ht. wt., heart weight at cropsy; +, dead. 
Table 3 Echocardiographic findings in two siblings and seven parents with isolated asymmetric septal hypertrophy

\begin{tabular}{|c|c|c|c|c|c|c|c|c|}
\hline Pedigree No. & Sex & Age & $B S A$ & $\underset{(m m)}{I V S}$ & $\begin{array}{l}\text { Predicted IVS at } \\
95 \% \text { interval }\end{array}$ & $\begin{array}{l}P L V W \\
(m m)\end{array}$ & $\begin{array}{l}\text { Predicted PLVW } \\
\text { at } 95 \% \text { interval }\end{array}$ & Other findings \\
\hline $\begin{array}{l}\text { Two siblings } \\
\text { 73.II. } 2 \\
\text { 82.II. } 2 \\
\text { Seven parents }\end{array}$ & $\begin{array}{l}\mathbf{F} \\
\mathbf{M}\end{array}$ & $\begin{array}{l}46 \\
18\end{array}$ & $\begin{array}{l}1 \cdot 70 \\
1 \cdot 76\end{array}$ & $\begin{array}{l}\star \\
12 \\
13\end{array}$ & $\begin{array}{l}\star \star \\
11.74 \\
10.95\end{array}$ & $\begin{array}{l}\star \\
9 \\
9\end{array}$ & $\begin{array}{l}\star \star \\
11 \cdot 26 \\
10.47\end{array}$ & $\begin{array}{l}\text { Im IVS } \\
\text { Im IVS }\end{array}$ \\
\hline $\begin{array}{l}\text { 24.I. } \\
\text { 32.I.1 } \\
\text { 33.I.1 } \\
\text { 82.I.1 } \\
\text { 93.I.1 } \\
\text { 96.I.2 } \\
\text { 97.I.1 }\end{array}$ & $\begin{array}{l}\mathbf{F} \\
\mathbf{M} \\
\mathbf{M} \\
\mathbf{M} \\
\mathbf{F} \\
\mathbf{F} \\
\mathbf{M}\end{array}$ & $\begin{array}{l}78 \\
53 \\
67 \\
51 \\
74 \\
65 \\
66\end{array}$ & $\begin{array}{l}1.60 \\
1.87 \\
1.94 \\
1.88 \\
1.42 \\
1.68 \\
1.96\end{array}$ & $\begin{array}{l}16 \\
15 \\
15 \\
18 \\
15 \\
17 \\
19\end{array}$ & $\begin{array}{l}12 \cdot 61 \\
12 \cdot 42 \\
13.06 \\
12 \cdot 37 \\
12 \cdot 02 \\
12 \cdot 45 \\
13 \cdot 10\end{array}$ & $\begin{array}{l}10 \\
10 \\
10 \\
10 \\
10 \\
10 \\
-\end{array}$ & $\begin{array}{l}12 \cdot 12 \\
11.96 \\
12.57 \\
11.87 \\
11.53 \\
11.92 \\
12.60\end{array}$ & $\begin{array}{l}\text { Im IVS } \\
\text { Im IVS } \\
\text { Im IVS } \\
\text { Im IVS } \\
- \\
\overline{\text { PM Ht wt } 602 \mathrm{~g}}\end{array}$ \\
\hline
\end{tabular}

*Actual measurements of IVS and PLVW obtained, compared with the $95 \%$ predicted limits from 92 normal subjects. ${ }^{\star \star H e n r y ~ e t ~ a l . ~}{ }^{29}$ The 3 following abbreviations have been used: Im IVS, impaired movement of interventricular septum; PM, post-mortem examination; Ht wt, heart weight at necropsy.

before accepting ratios of 1.3 or more above this age as being abnormal.

In the 12 families where not only the propositus but one parent had hypertrophic cardiomyopathy, one of the siblings had isolated asymmetric septal hypertrophy. Conversely, in the seven families where the propositus had hypertrophic cardiomyopathy and one of the parents isolated asymmetric septal hypertrophy, the seven propositi and six of their siblings had hypertrophic cardiomyopathy and only one sibling had isolated asymmetric septal hypertrophy. Therefore, a parent with either clinical hypertrophic cardiomyopathy or isolated asymmetric septal hypertrophy may produce an offspring with either manifestation of the disease, that is hypertrophic cardiomyopathy or isolated asymmetric septal hypertrophy.

In these 19 families there were 23 children. Assuming a dominant inheritance the expected number affected would be $11 \cdot 5$, but only three were found to have hypertrophic cardiomyopathy and two isolated asymmetric septal hypertrophy both of whom may also have bicuspid aortic valves as the echocardiograms showed eccentric aortic valve closure and in one (77.III.2) there was also a soft aortic diastolic murmur. (In 33.III.4 and 72.III.1 the diagnosis was doubtful and these children have therefore been considered normal in the statistical analysis.) The figure of five (three with hypertrophic cardiomyopathy and two with isolated asymmetric septal hypertrophy) does not differ significantly from the expected number $\left(\chi^{2}=2.8\right)$, though it is low, which may be because of underdiagnosis. The explanation for this in the younger age group is discussed elsewhere ${ }^{30}$ but we have increasing evidence that, though the disease is genetically determined, its clinical manifestations may not be evident until adolescence, or even early adult life. A good example of this was Family 99 . When first seen 99.II.1 and 99.II.2 were aged 11 and 9 years. They were asymptomatic, the cardiovascular findings were normal, in particular there were no murmurs, and both the electrocardiograms and chest radiographs were normal. Echocardiography was not available. When examined eight years later because the $\rightarrow$ younger (99.II.2) had had a synocopal attack while playing football, both had developed ejection murmurs. The electrocardiograms had become abnormal; $\ddot{\bullet}$ in the younger (99.II.2) there was T wave inversion in $\omega$ the left chest leads and equivalents, and in the elder (99.II.1) pathological $Q$ waves had developed in I, aVL, V5, and 6. Their chest radiographs had remained normal. The echocardiograms, previously unrecorded, were abnormal; in both there was a thick- $\mathbb{Q}$ ened immobile interventricular septum and the $\underset{\vec{F}}{\overrightarrow{2}}$ younger also showed systolic anterior movement of $\frac{\circ}{3}$ the mitral valve. The IVS/PLVW ratio was $1 \cdot 4$. Five years after this examination he died suddenly at the age of 22 years. The diagnosis of hypertrophic cardiomyopathy was confirmed at necropsy, the heart $\mathbb{D}$ weighing $430 \mathrm{~g}$. The interventricular septum meas- $\frac{}{?}$ ured $33 \mathrm{~mm}$ compared with the free wall of the left $\frac{\text { 익 }}{3}$ ventricle which was $20 \mathrm{~mm}$. The echocardiogram in the elder (99.II.1) when aged 19 years showed an 0 immobile and abnormally thick interventricular septum measuring 13 to $14 \mathrm{~mm}$. There was also음 thickening of the posterior left ventricular wall 11 to $>$ $12 \mathrm{~mm}$ giving an IVS/PLVW ratio of 1.2 which was within normal limits. After the inhalation of amyl $N$ nitrate, however, there was systolic anterior movement of the mitral valve. In this case the thickening of the posterior left ventricular wall tended to make the $\omega$ ventricular hypertrophy more symmetrical than usual, which is known to occur in some cases ofo hypertrophic cardiomyopathy. All causes of symmetrical hypertrophy such as hypertension and aortic ? valve stenosis had been excluded and the diagnosis of $\underline{T}$ hypertrophic cardiomyopathy was strongly supported in this case by the development of murmurs between the ages of 11 and 19 years, the changes in the elec- $\stackrel{\mathbb{2}}{2}$ trocardiograms during the same period, and the 
strongly positive family history: his brother, father, and father's sister all had proven hypertrophic cardiomyopathy.

It is uncertain whether some genetically determined cases of isolated asymmetric septal hypertrophy, that is those occurring in families in which there are no known cases of hypertrophic cardiomyopathy, progress and develop the full clinical picture of hypertrophic cardiomyopathy. There is some evidence that this may occur in children and in young adults, but after the age of 20 we have not seen isolated asymmetric septal hypertrophy alter with the years.

\section{GENETICS}

The fundamental problem is the genetic relation between asymmetric septal hypertrophy and hypertrophic cardiomyopathy. A survey of the published reports on the inheritance of asymmetric septal hypertrophy 181931 showed that the data have been ascertained through families in which there were proven cases of hypertrophic cardiomyopathy. Only Marcomichelakis et al. ${ }^{22}$ studied the normal population and looked at asymmetric septal hypertrophy in those subjects who were at the extreme of the distribution of septal thickness when allowance had been made for their age. Their findings confirmed that asymmetric septal hypertrophy was non-specific for hypertrophic cardiomyopathy.

The simplest genetic concept would be a single autosomal dominant gene which could be expressed in a mild (isolated asymmetric septal hypertrophy) or severe (hypertrophic cardiomyopathy) form. The problem, however, of the variation of expression within a family would remain unanswered. It could be postulated that there was either a gene for asymmetric septal hypertrophy which with genetic or environmental modifiers could be expressed as hypertrophic cardiomyopathy or, conversely, that there was a gene for hypertrophic cardiomyopathy which, with other genetic or environmental modifiers, could be expressed as isolated asymmetric septal hypertrophy. Whichever is the case the net effect is that the hypertrophic cardiomyopathy expression behaves like an autosomal dominant condition. Until a genetic study of asymmetric septal hypertrophy is done in its own right nothing can be said about its mode of inheritance. The suggestion that more than one factor is involved would fit the threshold model proposed by a number of authors in other conditions. ${ }^{32} 33$ Indeed there is evidence that part of the underiying liability for hypertrophic cardiomyopathy might be related to the HLA-DRW4 antigen linkage. ${ }^{34}$

The delayed clinical expression of hypertrophic cardiomyopathy in many cases and the fact that there is some evidence that isolated asymmetric septal hypertrophy may progress to hypertrophic car- diomyopathy suggest that the liability to asymmetric septal hypertrophy may be part of the underlying predisposition. It also suggests that the threshold for asymmetric septal hypertrophy is just below that for hypertrophic cardiomyopathy. Under these conditions such a complex genetic aetiology may simulate dominance.

By definition all patients with hypertrophic cardiomyopathy had asymmetric septal hypertrophy. If hypertrophic cardiomyopathy represents the increased severity of liability then both isolated asymmetric septal hypertrophy and hypertrophic cardiomyopathy may occur in the same family. This was the case in both the subsets studied and it would also explain the much greater incidence of hypertrophic cardiomyopathy than isolated asymmetric septal hypertrophy in any affected generation.

Our conclusion is that when a patient presents with isolated asymmetric septal hypertrophy if there is hypertrophic cardiomyopathy in the family, then either of them may be expected in $50 \%$ of the offspring. Any minor deviations from $50 \%$ are what one might expect from a complex trait simulating dominance.

We are grateful to the physicians and surgeons at the National Heart Hospital and to Professor John Goodwin and his colleages at the Hammersmith Hospital for access to their clinical material. We are also indebted to Ciba Laboratories for their continued support.

\section{References}

1 Henry WL, Clark CE, Epstein SE. Asymmetric septal hypertrophy (ASH): the unifying link in the IHSS disease spectrum: observations regarding its pathogenesis, pathophysiology, and course. Circulation 1973; 47: 82732.

2 Bulkley BH, Weisfeldt ML, Hutchins GM. Asymmetric septal hypertrophy and myocardial fiber disarray; features of normal, developing and malformed hearts. Circulation 1977; 56: 292-8.

3 Maron BJ, Verter J, Kapur S. Disproportionate ventricular septal thickening in the developing normal human heart. Circulation 1978; 57: 520-6.

4 Oakley GDC, Oakley CM. Abnormal electrocardiograms in athletes (abstract). Br Heart $\mathcal{F}$ 1980; 43: 123.

5 Maron BJ, Edwards JE, Ferrans VJ, et al. Congenital heart malformations associated with disproportionate ventricular septal thickening. Circulation 1975; 52: 92632.

6 Larter WE, Allen HD, Sahn DJ, Goldberg SJ. The asymmetrically hypertrophied septum: further differentiation of its causes. Circulation 1976; 53: 19-27.

7 Ibrahim Z, Schmaltz AA, Apitz J, Sadowski P. Asymmetric septal hypertrophy: pathognomy of idiopathic 
hypertrophic subaortic stenosis? European Cardiological Congress, Amsterdam, June 1976.

8 Maron BJ, Clark CE, Henry WL, et al. Prevalence and characteristics of disproportionate ventricular septal thickening in patients with acquired or congenital heart diseases: echocardiographic and morphologic findings. Circulation 1977; 55: 489-96.

9 Maron BJ, Edwards JE, Moller JH, Epstein SE. Prevalence and characteristics of disproportionate ventricular septal thickening in infants with congenital heart disease. Circulation 1979; 59: 126-33.

10 Maron BJ, Gottdiener JS, Roberts WC, Hammer WJ, Epstein SE. Nongenetically transmitted disproportionate ventricular septal thickening associated with left ventricular outflow obstruction. Br Heart f 1979; 41: 345-9.

11 Savage DD, Drayer JIM, Henry WL, et al. Echocardiographic assessment of cardiac anatomy and function in hypertensive subjects. Circulation 1979; 59: 623-32.

12 Henning H, O'Rourke RA, Crawford MH, Righetti A, Karliner JS. Inferior myocardial infarction as a cause of asymmetric septal hypertrophy: an echocardiographic study. Am $\mathcal{F}$ Cardiol 1978; 41: 817-22.

13 Stern A, Kessler KM, Hammer WJ, Kreulen TH, Spann JF. Septal-free wall disproportion in inferior infarction: the echocardiographic differentiation from hypertrophic cardiomyopathy. Circulation 1978; 58: 700-6.

14 Rossen RM, Goodman DJ, Ingham RE, Popp RL. Echocardiographic criteria in the diagnosis of idiopathic hypertrophic subaortic stenosis. Circulation 1974; 50: 747-51.

15 Maron BJ, Ferrans VJ, Henry WL, et al. Differences in distribution of myocardial abnormalities in patients with obstructive and nonobstructive asymmetric septal hypertrophy (ASH): light and electron microscopic findings. Circulation 1974; 50: 436-46.

16 Henry WL, Clark CE, Roberts WC, Morrow AG, Epstein SE. Differences in distribution of myocardial abnormalities in patients with obstructive and nonobstructive asymmetric septal hypertrophy (ASH): echocardiographic and gross anatomic findings. Circulation 1974; 50: 447-55.

17 Clark CE, Henry WL, Epstein SE. Familial prevalence and genetic transmission of idiopathic hypertrophic subaortic stenosis. N Engl f Med 1973; 289: 709-14.

18 Van Dorp WG, Ten Cate FJ, Vletter WB, Dohmen H, Roelandt J. Familial prevalence of asymmetric septal hypertrophy. Eur $\mathcal{F}$ Cardiol 1976; 4: 349-57.

19 Ten Cate FJ, Hugenholtz PG, Van Dorp WG, Roelandt $\mathrm{J}$. Prevalence of diagnostic abnormalities in patients with genetically transmitted asymmetric septal hypertrophy. Am f Cardiol 1979; 43: 731-7.

20 Emanuel $R$, Withers R, O'Brien $\mathrm{K}$, Feizi $\mathrm{O}$. Studies of the hereditary aspects of cardiomyopathy. 6th AsianPacific Congress of Cardiology, Honolulu, October 1976. Abstract, p.l.
21 Emanuel R, Withers R, O'Brien K, Feizi O. Asymmetric septal hypertrophy in hypertrophic cardiomyopathyincreasing thickness of the intraventricular septum with age. In: Anand MP, Shah SJ, eds. Progress in cardio pulmonary disease. Bombay: States People Press, 1979: 401-6.

22 Marcomichelakis J, Withers R, Newman GB, O'Brien $\mathrm{K}$, Emanuel R. The importance of age in assessing the significance of the thickness of the interventricular septum, posterior left ventricular wall and their ratio: an echocardiographic study of a normal male population. Int $\mathcal{f}$ Cardiol (Submitted for publication).

23 Emanuel R, Ng RAL, Marcomichelakis J, et al. Formes frustes of Marfan's syndrome presenting with severe aortic regurgitation: clinicogenetic study of 18 families. $\mathrm{Br}$ Heart F 1977; 39: 190-7.

24 Emanuel R, Nichols J, Anders JM, Moores EC, Somerville J. Atrioventricular defects-a study of 92 families. Br Heart $\mathcal{F}$ 1968; 30: 645-53.

25 Emanuel R, O'Brien K, Somerville J, Jefferson K, Hegde $M$. Association of secundum atrial septal defect with abnormalities of atrioventicular conduction or left axis deviation: genetic study of 10 families. $\mathrm{Br}$ Heart $\mathrm{J}$ 1975; 37: 1085-92.

26 Emanuel R, Withers R, O'Brien K. Dominant and recessive modes of inheritance in idiopathic cardiomyopathy. Lancet 1971; ii: 1065-7.

27 Emanuel R, Withers R, O'Brien K, Ross P, Feizi O. Congenitally bicuspid aortic valves. Clinicogenetic study of 41 families. Br Heart $\mathcal{F}$ 1978; 40: 1402-7.

28 Smith CAB. A test for segregation ratios in family data. Ann Hum Genet 1956; 20: 257-65.

29 Henry WL, Gardin JM, Ware JH. Echocardiographic measurements in normal subjects from infancy to old age. Circulation 1980; 62: 1054-61.

30 Emanuel $R$, Withers $R$, O'Brien $K$. The inheritance of hypertrophic cardiomyopathy. VIIth Asian-Pacific Congress of Cardiology, Bangkok, 1979. (Submitted for publication.)

31 Bingle GJ, Dillon J, Hurwitz R. Asymmetric septal hypertrophy in a large Amish kindred. Clin Genet 1975; 7: 255-61.

32 Carter CO. Genetics of common disorders. Br Med Bull 1969; 25: 52-7.

33 Edwards JH. Familial predisposition in man. Br Med Bull 1969; 25: 58-64.

34 Matsumori A, Kawai C, Wakabayashi A, et al. HLA- $\rightarrow$ DRW4 antigen linkage in patients with hypertrophic obstructive cardiomyopathy. Am Heart $\mathcal{f}$ 1981; 101: N $14-6$.

Requests for reprints to Dr Richard Emanuel, $\mathcal{G}$ National Heart Hospital, Westmoreland Street, London W1M 8BA. 